\title{
PLANEJAMENTO PARA A ATUAÇÃO COM A EDUCAÇÃO FÍSICA ESCOLAR: REFLEXÕES A PARTIR DO PROGRAMA INSTITUCIONAL DE BOLSA DE INICIAÇÃO A DOCÊNCIA- PIBID- CEFD/UFSM
}

\author{
B. C. PATIAS*, A. A. IVO, L. C. COSTA, E. C. MARIN \\ Universidade Federal de Santa Maria - UFSM \\ bhiiancacp@gmail.com*
}

Submetido 14/08/2017 - Aceito 12/06/2018

DOI: $10.15628 /$ holos.2018.4834

\section{RESUMO}

Este trabalho tematiza o planejamento, objetivando compreender a elaboração e desenvolvimento do planejamento para ação docente com a Educação Física (EF) no contexto do PIBID EF do CEFD/UFSM. Para levantamento dos dados foram realizadas entrevistas com doze bolsistas, seis supervisores e dois coordenadores. Os dados demonstraram que apesar de historicamente o planejamento pedagógico na $E F$ escolar possuir fragilidades e, por vezes se resumir ao cumprimento de obrigações burocráticas, no contexto do subprojeto PIBID Educação Física o planejamento tem assumido relevância nas reuniões e na ação docente dos envolvidos.

PALAVRAS-CHAVE: Educação Física Escola, Planejamento, PIBID.

\section{PLANNING FOR THE WORK WITH THE SCHOOL PHYSICAL EDUCATION: REFLECTIONS FROM THE INSTITUTIONAL SCHOLARSHIP PROGRAM INTRODUCTION TO TEACHING - PIBID- CEFD / UFSM}

\section{ABSTRACT}

This paper aims to understand the design and development planning for physical education (PE) pedagogical practice in the context of PIBID PE of CEFDUFSM. For data collection it was done interviews with twelve fellows, six supervisors and two coordinators. Even though historically the PE pedagogical planning at schools have weaknesses and sometimes it is reduced to the fulfillment of bureaucratic requirements, the data demonstrated that Physical Education planning in PIBID subproject has assumed relevance in meetings and in pedagogical practice of those involved.

KEYWORDS: Physical Education Educational, Planning, PIBID. 


\title{
1 INTRODUÇÃO
}

Diversos autores, com diferentes perspectivas, têm dedicado atenção ao planejamento no processo educativo formal. Clermont Gauthier é professor titular, da Faculdade de Ciências da Educação na Universidade Laval (Québec- Canada) e em entrevista concedida a Ivo e Dencuff (2014), por exemplo, menciona que o trabalho do professor é mediado por duas grandes funções: a gestão de classe e a gestão da aprendizagem. A gestão da classe refere-se a transmissão de valores e comportamentos, já a função pedagógica da gestão de aprendizagem diz respeito a todos os enunciados relativos ao planejamento, ao ensino e a avaliação do processo de ensino e aprendizagem. Ou seja, o conjunto de operações que o professor lança mão para levar os alunos a aprender o conteúdo. $O$ autor situa que essas duas grandes funções são complementares e necessárias para o trabalho do professor.

Canfield (1996) considera o planejamento como a "pedra fundamental", como a razão de todo trabalho docente consciente. Diz respeito a todas as ações e decisões do professor na sua relação com os seus discentes, por isso, trata-se de uma programação realizada e avaliada pelo professor cotidianamente, como processo, flexível, inacabado, aberto a mudanças e reestruturações.

Para Libâneo (2013, p. 245) o planejamento de ensino:

\begin{abstract}
“É uma tarefa docente que inclui tanto a previsão das atividades didáticas em termos de sua organização e coordenação em face dos objetivos propostos, quanto a sua revisão e adequação no decorrer do processo de ensino. O planejamento é um meio para se programar as ações docentes, mas é também um momento de pesquisa e reflexão intimamente ligado a avaliação".
\end{abstract}

Ou seja, o planejamento é fundamental para o professor manter um acompanhamento de suas atividades didáticas, e também verificar os resultados provenientes da sua atuação, bem como verificar fragilidades e possibilidades de alterações. A elaboração do planejamento envolve refletir e buscar responder os seguintes questionamentos: Como? Com quê? O quê? Para quê? Para quem? Por quê? (atento às necessidades e características das turmas e dos alunos). Esses elementos são adotados como ponto de partida para o professor começar a formular o seu planejamento.

Assim, essa pesquisa tem como objetivo compreender a elaboração e o desenvolvimento do planejamento à ação docente com a Educação Física no contexto do PIBID Educação Física da Universidade Federal de Santa Maria (UFSM). O PIBID é um Programa proposto pelo Ministério da Educação no ano de 2007, com vistas à valorização da formação de professores para atuação na educação básica, que visa promover a inserção de acadêmicos de licenciatura no contexto das Escolas Públicas, desde o inicio da sua formação ${ }^{1}$, desenvolvendo atividades didático-pedagógicas sob orientação de um docente da licenciatura (Coordenador de área) e de um professor da escola (Professor Supervisor).

\footnotetext{
${ }^{1}$ Anteriormente para participar do PIBID do CEFD/UFSM havia o pré requisito de estar cursando o $3^{\circ}$ semestre em diante, fato que mudou nas últimas seleções, onde todos os alunos podem participar, desde do $1^{\circ}$ semestre.
} 
O Subprojeto PIBID Educação Física na Educação Básica edital 61/2013, está estruturado de maneira a atender todos os níveis de ensino da Educação Física Escolar, subdividido em: Educação Infantil, Anos Inicias e Anos Finais do Ensino Fundamental e Ensino Médio. Cada nível de ensino possui um Coordenador de Área responsável, docente do Centro de Educação Física e Desporto (CEFD/UFSM).

\section{METODOLOGIA}

Assim como Marin (2006), entendemos a pesquisa como oficio semelhante do artesão, onde se parte de um estado confuso, com hesitações, renúncias, decisões, e ao final chega-se ao seu estado "acabado", a partir de sucessivos retoques, tensões, retrocessos, avanços.

Este estudo insere-se na perspectiva da pesquisa exploratória que, de acordo com Deslandes (2007), consiste na produção do projeto de pesquisa e de todos os procedimentos necessários para a entrada em campo. Segundo Marin (2006), esse primeiro contato exploratório possibilita diversos encaminhamentos em termos de recortes de pesquisa.

Entrevistamos, a partir dos pressupostos de Minayo (2007), os Coordenadores (CO) de Área, Professores Supervisores (PS) e os Bolsistas de Iniciação a Docência (BID) ${ }^{2}$ do PIBID Educação Física na Educação Básica, dos Subprojetos Anos Iniciais (Al) do Ensino Fundamental, e Anos Finais (AF) do Ensino Fundamental (a escolha pelo Ensino Fundamental se deu por este abranger a maior parte dentro da Educação Básica).

Foram entrevistados 20 colaboradores, 12 Bolsistas de Iniciação a Docência, 6 de cada subprojeto; 6 Professores Supervisores, 3 de cada subprojeto; e 2 coordenadores, 1 de cada subprojeto. Seguindo pressupostos éticos todos foram convidados a assinar o Termo de Consentimento Livre e Esclarecido, onde continha informações sobre os objetivos da pesquisa que garante o sigilo da identidade dos entrevistados, também dando liberdade para que o colaborador pudesse desistir da pesquisa a qualquer momento. Visando o sigilo dos nomes dos colaboradores, os Bolsistas de Iniciação a Docência foram nomeados BID 1 à 12; os Professores Supervisores de PS 1 à 6 e o Coordenador do Anos Finais CO1 AF e Coordenador dos Anos Iniciais CO2 Al, respectivamente.

Para realização da coleta de dados foi estabelecido anteriormente um encontro, promovendo um diálogo com os colaboradores a fim de explicar os objetivos da pesquisa e posterior agendamento dos dias e horários com os mesmos. As entrevistas foram gravadas mediante a autorização dos colaboradores, transcritas e analisadas sob os preceitos da análise de conteúdo, que, com base em Franco (2005), trata-se de um procedimento que considera a mensagem (oral, escrita, gestual, silenciosa, figurativa, documental ou diretamente provocada), e as condições contextuais dos seus produtores.

\footnotetext{
${ }^{2}$ O critério de seleção dos BIDs foi de estar vinculado ao subprojeto há no mínimo dois semestres, este recorte justifica-se pela experiência desenvolvida pelos mesmos na escola. Tendo em vista, que cada subprojeto atua em três escolas, foram selecionados dois BIDS de cada escola, totalizando 12 BIDS. O semestre que os BIDS estão cursando varia do $1^{\circ}$ ao $8^{\circ}$.
} 


\section{O PLANEJAMENTO DE ENSINO NO SUBPROJETO EDUCAÇÃO FÍsICA NA EDUCAÇÃO BÁSICA CEFD/UFSM}

O modo como o planejamento, ainda hoje, é concebido na Educação Física escolar, muito provável é reflexo da própria constituição histórica dessa área de conhecimento. Segundo Bracht (1999) desde meados dos séculos XVIII e XIX, a Educação Física era fortemente influenciada pelas instituições militares e pela medicina. A primeira, detentora das práticas e dos exercícios, e, a segunda, agregou significados a esses conhecimentos direcionando para a área da saúde. O papel da Educação Física era de desenvolver corpos saudáveis, fortes, e que estivessem em condições de servir aos sistemas de produção da época.

Entre os séculos XIX e XX, emergiu como prática corporal o esporte, que estava ligado a conceitos como o de rendimento, recordes, vitórias, dentre outros, o qual veio a se incorporar dentro da Pedagogia da Educação Física, sem modificações, ou seja, houve reprodução da forma como o esporte estava sendo imposto na sociedade. Os professores adotavam isso como meta, delimitando objetivos e traçando caminhos para atingi-los (JAHN, 2004).

Foi então no século XX, a partir dos anos 1980, que começa a surgir novas perspectivas teóricas a partir das quais se questiona na Educação Física a reprodução de atividades, de esportes, e propõem-se pensá-la como um amplo conhecimento sobre a cultura corporal (BRACHT, 2010), esse período foi conhecido como Movimento Renovador da Educação Física.

Apesar da ampliação teórica da área, o planejamento voltado à reprodução do esporte de rendimento continua presente, no sentido de que se pode verificar um grande destaque para o desenvolvimento do esporte na maioria das escolas. Segundo Krug (2002), muitos professores têm dificuldade em colocar no papel os objetivos norteadores de uma prática que esteja distante dos seus gostos e preferências, priorizando o ensino mais próximo da sua experiência. $O$ referido identificou que os professores fundamentam suas práticas pedagógicas a partir de suas experiências, de suas vivências, pelo que consideram dar ou não resultado, entendendo o planejamento como tarefa para os professores que estão iniciando na carreira ou menos "experientes".

Conforme Silva \& Gonzales (2016, p.56) a trajetória histórica da Educação Física foi marcada por atividades práticas, ocasionando dificuldade em firmar conhecimentos conceituais, ou seja, "ausência de planejamento". Ou no entendimento de Caparroz e Bracht (2007, p.23) têm estreita relação com os cursos de formação de professores de Educação Física, "por não estarem preparando os futuros profissionais para operarem tarefas primordiais do trabalho docente, como é o caso do planejamento".

Numa tentativa de ruptura com as práticas vigentes na Educação Física escolar o Subprojeto PIBID Educação Física, tem incluído nas discussões do grupo a importância do planejamento para o desenvolvimento das aulas. O Subprojeto conta com sessenta Bolsistas de Iniciação a Docência, doze Professores Supervisores e quatro Coordenadores de Área. Os Bolsistas de Iniciação a Docência cumprem dois turnos na escola durante a semana, juntamente com o Professor Supervisor, responsável por sua atuação no âmbito escolar. Ademais, os Coordenadores de área por cada nível de ensino realizam reuniões de estudos ${ }^{3}$, semanalmente, para

\footnotetext{
${ }^{3}$ Participam das reuniões os coordenadores, supervisores e bolsistas de iniciação a docência. As reuniões tem em média a duração de 3 horas.
} 
acompanhamento e orientação dos seus bolsistas. Dessa forma quando entrevistados os Coordenadores ao se referir as reuniões mencionam que:

\begin{abstract}
“As reuniões são semanais. A gente está fazendo, primeiro o planejamento, ter uma direção metodológica para o trabalho, ou seja, ter um objetivo e estar bem amarrado com o conteúdo, com as atividades que vai trabalhar, com o processo de avaliação, ou seja, com o objetivo e o conteúdo. A gente está se formando pra isso, trabalhamos textos teóricos sobre isso. Eu trouxe pra eles alguns planejamentos no sentido de como se pode elaborar. E agora está na fase de discutirmos os planejamentos desenvolvidos por eles na escola. Dentro dessa lógica que nós aprendemos." (CO2 Al)
\end{abstract}

“[...] nós trabalhamos com leituras básicas, principalmente relativas às abordagens da Educação Física. O nosso projeto esse ano definiu uma abordagem, a críticosuperadora, então normalmente as leituras são direcionadas para essa abordagem. Mas também fizemos neste horário o processo de apresentação das dificuldades dos alunos, a gente tem seminários mensais de cada escola. Cada escola apresenta o seu programa e um exemplo do seu planejamento e abre para as discussões. Nós começamos a fazer isso no segundo semestre." (CO1 AF)

Ambos os coordenadores discutem o planejamento de ensino nas reuniões, o qual segundo Bossle (2002) pode ser subdividido em plano de disciplina, ou de curso, que é o que se faz para um ano ou semestre; o plano de unidade, que se refere a um item ou tópico de um programa (unidade de trabalho); e o plano de aula, que nada mais é do que um detalhamento do plano de ensino para a prática da sala de aula.

Ainda que o planejamento de ensino não seja o principal tema tratado pelo coordenador CO1 AF, visto que apresenta preocupação maior com o desenvolvimento da abordagem de ensino, a definição e clareza da abordagem auxilia os BID no planejamento, pois como adverte Libâneo (2013), para que um planejamento seja efetivamente um instrumento para a ação, entre outros aspectos, exige coerência entre as ideias e a prática, entre objetivos, conteúdos, métodos e avaliação.

Participam da elaboração e desenvolvimento do planejamento os coordenadores, supervisores e bolsistas, todavia com ações diferentes, mas complementares. No que se refere ao auxilio do PS e CO é possível verificar que ambos atuam dando suporte para que as ações pautadas no planejamento se efetivem. O PS elenca características e perfis imprescindíveis para o possível delineamento de um planejamento, enquanto que o CO direciona as discussões e planejamentos mais amplos que são realizados anteriormente.

\footnotetext{
“O professor lá da escola auxilia nas reuniões, dando dicas. Como ele já conhece a turma, ele diz: talvez isso aqui não vai funcionar, porque a turma é mais agitada ou menos. E o Coordenador atua de uma forma mais geral, mais ampla, falando mais sobre as abordagens, como que tem utilizado dentro do plano de aula" (BID11 AF)
}

Ambas as orientações são importantes, visto que os PS auxiliam o planejamento das aulas de uma forma mais próxima aos BIDs, pelo fato de serem professores dessas turmas 
anteriormente, o que é um facilitador por já terem conhecimento sobre as turmas e alunos as quais esse planejamento será direcionado, dessa forma o BID 2 Al ao ser entrevistado evidencia que:

\begin{abstract}
“A reunião com o coordenador é, no mínimo uma vez por mês. Nós chegamos na reunião e apresentamos o planejamento e o coordenador questiona se aquilo que nós estamos trabalhando é adequado segundo a nossa concepção e por que é importante. $O$ supervisor, auxilia na reunião também, junto com a coordenadora, mas principalmente na escola. A gente reelabora o plano e manda pra ele, e ai, ele nos questiona. Ele faz praticamente quase a mesma coisa que a coordenadora, só que na escola, ele está ali, está vendo como tá funcionando, e também durante a aula, ele questiona será que é assim, como que vocês vão trabalhar dessa forma" (BID $2 \mathrm{Al}$ ).
\end{abstract}

O planejamento é elaborado/pensado conforme a realidade que os BIDs encontram no contexto escolar em que estão inseridos, conforme suas falas:

\begin{abstract}
“O planejamento que a gente faz é em cima de coisas que eles conhecem, a gente trabalha um pouco de esportes coletivos, e agora estamos dando um enfoque para os jogos cooperativos, que é para fazer com que eles tenham uma integração maior, a questão da aula mesmo" (BID $11 \mathrm{AF}$ ).
\end{abstract}

\begin{abstract}
"A gente faz um planejamento conforme a gente vê que eles precisam na hora do jogo, que eles não estão sabendo, não estão conseguindo entender, procuramos enfatizar. Nós começamos a planejar, a partir das necessidades que a gente vê neles" (BID $12 \mathrm{AF}$ ).
\end{abstract}

É possível verificar que o conteúdo dos esportes está presente relacionado a realidade escolar, seguido dos jogos cooperativos no intuito de proporcionar uma maior socialização e integração dos alunos. Além disso, em relação ao planejamento, Libâneo (2013) assinala que não se restringe a sala de aula, ele vai além, está ligado a exigências sociais e também as experiências dos alunos. Portanto ao planejar, os BIDs necessitam atentar ao contexto escolar e social dos mesmos.

Os coordenadores nas reuniões possibilitam aos BIDs, discussão, compreensão mais ampla e conhecimentos $t$ teóricos acerca do planejamento (do pensar e elaborar) e no que tange o trabalho desenvolvido na escola (posterior). Já os supervisores, articulados com os Coordenadores, acompanham o processo de execução e ação do planejamento, dessa forma por estarem juntos com os BIDs no contexto escolar, auxiliam no desenvolvimento das aulas e na avaliação do planejamento. Nesta relação entre CO, PS e BIDs o PIBID dos subprojetos analisados favorece uma experiência cuja práxis permite aos discentes do curso de licenciatura em Educação Física apropriação do processo do fazer docente e principalmente a pensar, situar-se e construir-se como professores.

Os participantes do subprojeto ressaltam a importância do planejamento para o desenvolvimento das aulas, como elucidam os seguintes relatos: 
“[...] considero muito importante, porque o planejamento é uma base pra ti chegar na escola, eu não consigo chegar na escola e trabalhar sem ter um planejamento, fica sem chão. Esse tempo também é importante pra refletir. Claro, a gente usa reflexão depois também do planejamento mas antes no que tu vai planejar é importante saber porque vou trabalhar certo conteúdo, a gente começa a pensar o porque que a gente vai trabalhar, o que que nós vamos desenvolver" (BID 2 AI)

\begin{abstract}
“O planejamento vai ser a tua referencia, de ver se foi possível, não foi possível, pra inclusive replanejar novos conhecimentos, novos objetivos, a partir daquilo que tu tens. É o teu fio, é onde tu consegue dar continuidade para aquilo. Então o planejamento pra mim é essencial, alguém que vai para um prática pedagógica sem planejamento o que quer desenvolver ali, eu acho que assim, acaba trabalhando os conhecimentos de forma muito fragmentado, se perde". (CO2)
\end{abstract}

\begin{abstract}
"O planejamento é algo primordial para que todo um trabalho seja bem desenvolvido e que realmente esteja voltado para o desenvolvimento da aprendizagem do aluno. O planejamento dentro de uma escola é toda uma sequencia de trabalho. Então nós estamos procurando fazer o possível, para que aconteça esses planejamentos (PS2AI)".
\end{abstract}

Os relatos evidenciam a centralidade que o planejamento assume na práxis docente, diferindo das experiências investigadas por Krug (2002); Bossle (2002); Silva \& Gonzales (2016), em que o planejamento tem como principal objetivo cumprir exigências formais ao invés de ser ação fundamental para as práticas diárias dos professores. Aparentemente, o ensino para muitos professores se constitui numa prática que não necessita ser pensada. Como pontua Silva \& Gonzales (2016) as chamadas "semanas de planejamento escolar", são momentos, de preenchimento de formulários, cumprimento de deveres burocráticos, onde os professores colocam o que vai ser trabalhado durante o ano, ou semestre, seus objetivos, conteúdos, atividades, materiais didáticos, métodos de ensino, avaliação e cronograma.

Como pode ser identificado nas falas abaixo, o planejamento de ensino é entendimento pelos professores supervisores como uma construção orientadora da ação docente, como processo organizador, direcionador, articulado com os objetivos, mas flexível.

\footnotetext{
“O planejamento é um norte, uma base para conseguirem seguir, conforme for acontecendo a aula. As vezes são necessárias algumas alterações, algumas observações, pra que a aula transcorra da melhor forma possível (PS 5 AF).
}

\begin{abstract}
"Eu acho que enriqueceria muito mais o trabalho pedagógico se tu usar o planejamento como um apoio, como um norte que tu tem que seguir, mas ele não pode sobremaneira, ser a ultima palavra. Olho pro papel o que está ali tenho que fazer, não! É um norte de quais atividades tu tem que fazer, tu tem que perceber a turma, o que os alunos estão gostando. O professor também tem que perceber como é que ele está trabalhando aquilo e se os alunos não estão conseguindo fazer aquilo, mas não está no planejamento, quem sabe ele organiza uma atividade facilitadora para aquele exercício que o aluno está fazendo, mesmo que não esteja no planejamento. Parte do professor perceber o que os alunos não conseguiram
\end{abstract}


realizar na atividade, por que era muito difícil, e aí elaborar uma nova estratégia" (PS 1, AI)

As percepções advindas do desenvolvimento do planejamento podem muitas vezes nortear um caminho diferente do que estava previsto levando em consideração o perfil e a aprendizagem dos alunos no momento da execução, dessa forma as ponderações dos PS corroboram com Libâneo (2013) ao advertir que o planejamento precisa ter flexibilidade, pois se trata de um guia e não de uma decisão inflexível. Portanto, é primordial adequar as propostas previstas no planejamento ao modo como os conteúdos vão sendo desenvolvidos, uma vez que, durante a aula, poderão surgir situações que não estavam previstas, tendo em vista a dinamicidade presente no contexto educacional.

Identificamos que a preocupação na compreensão e elaboração do planejamento de ensino por parte dos Coordenadores considera o conhecimento a ser trabalhado na Educação Física. Já nas falas dos Supervisores e Bolsista, a concepção de planejamento está centrada no executar, na atividade, no gosto do aluno, entre outros, historicamente assentado numa concepção de Educação centrada na ação motora. Evidenciando que tanto há avanços do PIBID em análise no que tange ao planejamento na EF quanto reprodução ao historicamente instituído (Marin, Sauer \& Gunther, 2016).

Outro aspecto importante a se considerar no planejamento refere-se à avaliação do mesmo, pois como sustenta Luckesi (2011, p. 184) "enquanto o planejamento traça previamente os caminhos, a avaliação subsidia os redirecionamentos que venham a se fazer necessários no percurso da ação". Nessa direção a avaliação do planejamento se mostra como aspecto importante para os BIDs:

\footnotetext{
"Praticamente em todas as aulas eu faço uma autoavaliação. Faço anotações, sobre o que foi importante, o que foi legal, o que não foi legal, o que não rendeu. $E$ acontece em todas as aulas, nem sempre tudo vai dar certo, mas a reflexão ela sempre acontece. E eu penso que seja de forma positiva, porque é importante para dar sequencia no trabalho" (BID 2 Al).
}

“A gente faz essa avaliação com os alunos todo final da aula e anotamos, fazemos um relatório no final do plano com tudo que aconteceu. É semanal, e tem avaliação também do grupo em geral, que a gente fala como foi o semestre" (BID 12 AF).

A avaliação é um processo central que aponta fragilidades da trajetória percorrida ao mesmo tempo em que elenca as ações desenvolvidas possibilitando vislumbrar novos caminhos de atuação e aprendizagem que atendam aos objetivos que foram previamente definidos no planejamento.

Apesar das dificuldades citadas pelos BIDs na elaboração e desenvolvimento do planejamento, como a falta de infraestrutura adequada; o comportamento dos alunos; a escolha e continuidade dos conteúdos e o pouco tempo para planejar as aulas, todos consideram que a participação no subprojeto contribuiu significativamente para seu aprendizado sobre os elementos que envolvem o planejamento. 
“O PIBID me ajuda muito, me ajudou e está me ajudando muito. Com a questão de aprender a fazer o planejamento, porque eu tenho o apoio da professora da escola e o apoio do coordenador que nos ajudam. Não que no dia a dia das aulas da graduação não tenha isso, mas é que é quase como uma aula particular, atendimento especial, separado" (BID $12 \mathrm{AF}$ ).

“Em relação ao planejamento, eu penso que nas disciplinas que a gente tem na graduação ele é trabalhado, mas de uma forma muito superficial e digamos fictícia. Tu planeja, mas tu não executa. No PIBID é diferente, tu planeja, tu vai lá e executa, ai a partir disso tu consegue ver se está dando certo, se a tua abordagem, teu método de ensino está dando certo, se é o melhor método ou não" (BID $2 \mathrm{Al}$ ).

O planejamento ganha um enfoque especial no PIBID, pois através das falas dos BIDs fica evidenciado que tanto a parte de elaboração quanto a execução se tornam mais evidentes, clarificando as dúvidas provenientes dos conhecimentos advindos da formação juntamente com as ações resultantes da prática. Como diversos estudos tem destacado Dalla Nora (2015); Mundt, Ivo \& Marin (2016); Welter, Welter e Sawitzki (2012) o PIBID tem assumido um importante espaço na formação inicial dos acadêmicos, pois proporciona práticas educacionais de docência no contexto escolar, visto que na formação inicial, existem atualmente, poucas disciplinas que proporcionam experiências dentro desse contexto ${ }^{4}$. No âmbito do planejamento de ensino, a experiência no PIBID possibilita elaborar/pensar o ensino e refletir/avaliar a ação docente como apontam os seguintes relatos:

\begin{abstract}
“O PIBID me auxilia principalmente para o fato de eu estar junto com pessoas que já fazem planejamento [...] o PIBID ele me possibilita estar inserido na escola antes de formado, então estar nesse meio junto com professores que fazem isso há mais tempo que tem um conhecimento maior que o meu acadêmico, me auxilia na questão do planejamento e poder ver as aulas." (BID $11 \mathrm{AF}$ )
\end{abstract}

\footnotetext{
"Eu acho que é um espaço onde a gente está na escola, a gente aprende a planejar junto com os outros, pode trocar ideias, então é muito importante, é um espaço a mais de formação." (BID 5 Al)
}

Os depoimentos dos BIDs condizem à possibilidade de articular os conhecimentos teóricos com a experiência docente dos PS e CO, de modo que as discussões nas reuniões dos subprojetos instrumentalizam a ação docente, segundo Rêgo (2006,p.101) "a literatura sobre formação de professores aponta a articulação teoria-prática como uma das questões fundamentais a ser considerada nos processos de formação inicial e/ou continuada".

\footnotetext{
${ }^{4}$ No caso do Cursos de Educação Física Licenciatura do CEFED/UFSM, a matriz curricular possui apenas duas disciplinas obrigatórias, que tem relação direta com o contexto escolar, sendo elas: a Didática e o Estágio Curricular Supervisionado.
} 


\section{CONSIDERAÇÕES FINAIS}

Historicamente o planejamento de ensino na Educação Física escolar, possui fragilidades, centrado num rol de atividades a serem desenvolvidas, isolado dos demais aspectos que evolvem o trabalho docente - método, objetivos, avaliação, conteúdos - e muitas vezes se resume ao cumprimento de obrigações burocráticas.

Todavia no contexto do subprojeto PIBID Educação Física o planejamento tem assumido relevância nas reuniões e na ação docente dos BID, se constituindo em um espaço que possibilita troca de experiências entre BID, PS e CO, a partir das discussões com os colegas e do acompanhamento do planejamento.

É possível identificar que os três segmentos envolvidos no programa em análise - BIDs, PS e CO - assinalam que o planejamento serve de referência para a atuação na escola, ou seja, é um caminho a seguir e, como tal, construído a partir do contexto social da escola e dos alunos. 0 planejamento processual e flexível, deve ter em vista que nem sempre a teoria mais adequada é a mais eficiente para o bom desenvolvimento de uma aula, pois tudo pode mudar, devido a dinamicidade que se apresenta no âmbito escolar e principalmente, considerando as características e especificidades de cada aluno. Outros aspectos a serem ponderados nesse processo condizem com a falta de infraestrutura nas escolas, o comportamento dos alunos, a escolha e continuidade dos conteúdos, visto que muitas escolas atualmente atravessam um momento de recursos escassos que inviabilizam a prática e desmotivam os professores e alunos.

A partir da experiência com o PIBID os PS que antes tinham uma visão reduzida à ação e ao planejamento, passam a ter um olhar mais amplo, um olhar sobre o todo (planejar, desenvolver e avaliar) o que possibilita que identifiquem as lacunas no planejamento realizado outrora, para que posteriormente possam ser modificadas.

É relevante destacar que identificamos que há diferenças no tratamento destinado ao planejamento pelos COs participantes do programa, pois cada profissional conduz de forma diferente a sua organização e dinâmica de desenvolvimento das atividades o que direta ou indiretamente influência na maneira como os PS e BIDs direcionam a elaboração, a organização e o desenvolvimento do planejamento.

É provável que essas mudanças de percepções ocorram pela dinâmica que o PIBID disponibiliza quanto ao tempo destinado às reuniões gerais e especificas que possibilitam que os sujeitos envolvidos com o projeto, frequentem as rodas de debates com os colegas que estão em realidades semelhantes viabilizando a troca de saberes e conhecimentos necessários para a sua prática pedagógica permitindo assim que planejem ,avaliem e reflitam sobre o sua prática.

A partir do exposto concluímos que o PIBID CEFD/UFSM, é um Programa significativo , pois proporciona a interação entre a Formação Inicial dos acadêmicos com a Escola, dando oportunidade de atuação simultânea, experimentando, discutindo, tencionando, avaliando, possibilitando assim uma compreensão mais aprofundada sobre o planejamento no processo de ensino escolar, assim como a construção desse conhecimento através das reuniões e trocas de experiências.

O trabalho coletivo dos professores e alunos que é organizado no PIBID ganha consistência na medida em que há inter-relação entre universidade, escola e formação, possibilitando dessa forma a complementação da percepção a respeito do planejamento, pois une a visão dos CO mais 
preocupada com o conteúdo/teoria e a visão do PS e BIDs mais pautada no executar, que leva a uma nova percepção do planejamento, mais ampla e completa, que pode ser o inicio de um caminho de mudança, para que no futuro possamos conceber o planejamento escolar como peça fundamental na Educação Física Escolar.

\section{REFERÊNCIAS}

Barbosa, C. L. D. A., \& de Alvarenga, L. (2010). Educação física e didática: um diálogo possível e necessário. Petrópolis, RJ: Vozes.

Bossle, F. (2002). Planejamento de ensino na educação física - uma contribuição ao coletivo docente. Revista Movimento, 8(1), 31 - 39.

Bracht, V. (1999). A constituição das teorias pedagógicas da educação física. Cadernos Cedes. 19(48), 69-88.

. (2010). A educação física no ensino fundamental. Anais do I seminário nacional: currículo em movimento. Belo Horizonte, 1-14. Disponível em: http://portal.mec.gov.br/index.php?option=com_docman\&view=download\&alias=7170-3-6educacao-fisica-ensino-fundamental-walter-bracht\&category_slug=dezembro-2010pdf\&Itemid=30192.

Brasil, Ministério da Educação (2013). Programa institucional de bolsa de iniciação à docência Proposta - Edital no 61/2013. O edital dispõe sobre propostas de projetos a serem apoiados no âmbito do Programa Institucional de Bolsa de Iniciação à Docência(Pibid). Recuperado em 22 Maio, 2018, de https://www.capes.gov.br/images/stories/download/editais/Edital_061_2013_PIBID.pdf.

Canfield, M. de S.(1996). Planejamento das aulas de educação física: é necessário?. En: Canfield, M. de S., Isto é Educação Física.(pp. 21-32). Santa Maria: Jtc Editor.

Caparroz, F. E. \& Bracht, V. (2007). O tempo e o lugar de uma didática da educação física. Revista Brasileira de Ciências do Esporte, 28(2), 21-37.

Dalla Nora, D. (2015). O trabalho pedagógico no PIBID - "Cultura esportiva da escola" e suas repercussões para a formação inicial em educação física. Dissertação de Mestrado, Universidade Federal de Santa Maria, Santa Maria, Rio Grande do Sul, Brasil. Disponível em: http://repositorio.ufsm.br/handle/1/6729.

Deslandes, S.(2007). O projeto de pesquisa como exercício cientifico e artesanato intelectual. En: Minayo, M, Pesquisa social: teoria, método e criatividade.(pp. 31-60). Petrópolis, RJ: Vozes.

Franco, M. L. P. B.(2005). Análise de Conteúdo. Brasília: Liber Livro Editora.

Gamboa, S. S. (2000). A pesquisa na construção da universidade: compromisso com a aldeia num mundo globalizado. En: Lombardi, J. C., Pesquisa em Educação: história, filosofia e temas transversais. (pp...). Campinas, SP: Autores Associados: HISTERDBR. 
Ivo, A. A., \& Dencuff, M. P. (2014). O ensino explícito: um meio para tornar eficaz nosso saber pedagógico - entrevista com Clermont Gauthier. Revista Teias, 15(39), 268-280. Doi: 10.12957/teias.2014.24491.

Jahn, Â. B. (2004). O planejamento das aulas de educação física dos professores que atuam em uma escola pública de Santa Maria. Dissertação de Mestrado, Universidade Federal de Santa Maria, Santa Maria, Rio Grande do Sul, Brasil. Disponível em: http://repositorio.ufsm.br/bitstream/handle/1/6778/ANGELA\%20JAHN.pdf.

Krug, Hugo Norberto. (2002). Educação física escolar: temas polêmicos. Cadernos de Ensino, Pesquisa e Extensão, (53), 1-49.

Libâneo, J. C.(2013). Didática. São Paulo: Editora Cortez.

Luckesi, C. C.(2011). Avaliação da aprendizagem escolar: estudos e proposições. São Paulo : Editora Cortez.

Marin, E. C., Sauer, D. L. \& Gunther, M. C. C. (2016). O conteúdo da educação física escolar como sinônimo de atividade: reducionismo, implicações e possibilidades. En Kunz, E., Didática da Educação Física 4: Educação Física e Esportes na Escola. (pp.171-193). Ijuí: Editora Unijuí.

Marin, E.C. (2006). O oficio da pesquisa: processos do fazer. En: Maldonado, A.E et al., Metodologias de Pesquisa em Comunicação: olhares, trilhas e processos. (pp.65-90).Porto Alegre: Sulina.

Minayo, M. C.(2007).Trabalho de campo: contexto de observação, interação e descoberta. En: Minayo, M. C. ,Pesquisa Social: Teoria, método e criatividade. (pp. 61-77). Petrópolis, RJ: Vozes.

Mundt, P. R., Ivo, A. A. \& Marin, E. C. (2016). Desligamento de bolsistas de iniciação a docência do PIBID: reflexões a partir do subprojeto educação física. En Sawitzki, R. L, Da Rosa, C. L. L. \& Gama, M. E., iniciação à docência, reflexões e produção do conhecimento: PIBID educação física no CEFD/UFSM. (pp.227-247). Curitiba: CRV.

Rêgo, M. C. F. D. (2006). A formação docente no fazer e refazer da prática pedagógica. Tese de Doutorado, Universidade Federal do Rio Grande do Norte, Natal, Rio Grande do Norte, Brasil. Disponível em: ftp://ftp.ufrn.br/pub/biblioteca/ext/bdtd/MariaCFDR.pdf.

Silva, A. M. \& González, F. J. (2016). O planejamento de professores de educação física após a implementação da Lei Federal 11.738/2008 na rede estadual de ensino. Revista Querubim, 1(30), 55-60. Disponível em: http://www.uff.br/feuffrevistaquerubim/images/arquivos/zzquerubim_30_v_1.pdf.

Welter, J., Welter, R. \& Sawitzki,R. L. (2012). A contribuição do subprojeto PIBID/EDF no processo de planejamento das aulas de educação física para os anos iniciais. Cadernos de Formação RBCE, 3(1), p. 87-96. 